\title{
REVIEW
}

Open Access

\section{Blending integrated knowledge translation with global health governance: an approach for advancing action on a wicked problem}

\author{
Katrina Marie Plamondon ${ }^{1,3^{*}}$ (D) and Julia Pemberton ${ }^{2}$
}

\begin{abstract}
Background: The persistence of health inequities is a wicked problem for which there is strong evidence of causal roots in the maldistribution of power, resources and money within and between countries. Though the evidence is clear, the solutions are far from straightforward. Integrated knowledge translation (IKT) ought to be well suited for designing evidence-informed solutions, yet current frameworks are limited in their capacity to navigate complexity. Global health governance (GHG) also ought to be well suited to advance action, but a lack of accountability, inclusion and integration of evidence gives rise to politically driven action. Recognising a persistent struggle for meaningful action, we invite contemplation about how blending IKT with GHG could leverage the strengths of both processes to advance health equity.

Discussion: Action on root causes of health inequities implicates disruption of structures and systems that shape how society is organised. This infinitely complex work demands sophisticated examination of drivers and disrupters of inequities and a vast imagination for who (and what) should be engaged. Yet, underlying tendencies toward reductionism seem to drive superficial responses. Where IKT models lack consideration of issues of power and provide little direction for how to support cohesive efforts toward a common goal, recent calls from the field of GHG may provide insight into these issues. Additionally, though GHG is criticised for its lack of attention to using evidence, IKT offers approaches and strategies for collaborative processes of generating and refining knowledge. Contemplating the inclusion of governance in IKT requires re-examining roles, responsibilities, power and voice in processes of connecting knowledge with action. We argue for expanding IKT models to include GHG as a means of considering the complexity of issues and opening new possibilities for evidence-informed action on wicked problems.
\end{abstract}

Conclusion: Integrated learning between these two fields, adopting principles of GHG alongside the strategies of $I K T$, is a promising opportunity to strengthen leadership for health equity action.

Keywords: Integrated knowledge translation, global health governance, health equity, health inequities, knowledge-to-action, wicked problems, complexity

\footnotetext{
* Correspondence: katrina.plamondon@ubc.ca

${ }^{1}$ University of British Columbia, 3333 University Way, Kelowna, BC, Canada

${ }^{3}$ Interior Health, 505 Doyle Avenue, Kelowna, BC, Canada

Full list of author information is available at the end of the article
}

(c) The Author(s). 2019 Open Access This article is distributed under the terms of the Creative Commons Attribution 4.0 International License (http://creativecommons.org/licenses/by/4.0/), which permits unrestricted use, distribution, and reproduction in any medium, provided you give appropriate credit to the original author(s) and the source, provide a link to the Creative Commons license, and indicate if changes were made. The Creative Commons Public Domain Dedication waiver (http://creativecommons.org/publicdomain/zero/1.0/) applies to the data made available in this article, unless otherwise stated. 


\section{Background}

Problems described as 'wicked' earn the label from their inherent resistance to resolve; they are convoluted, reactive problems entangled in competing social interests and values $[1,2]$. The persistence of health inequities $[3,4]$ is a wicked problem [5] shaped by systems of power [5-10] and the social and structural determinants of health [11-13]. Robust evidence provides clear insights into their socio-political, economic and historic causes [14], and offers actionable policy solutions [15-18], making the persistence of health inequities a knowledge-to-action problem. However, efforts to advance evidence-informed action unfold in the same systems of social and political power that disproportionately advantage the already privileged and are generative of health inequities' wicked nature. Additionally, despite recognition of their wickedness, attempts to respond often reduce health inequities into component parts, examining 'symptoms' rather than causes [19-21] in ways that 'fit' with dominant political ideologies [22-24]. These factors fuel the wickedness and tenacity of health inequities.

The purpose of this review article is to explore the complementarities of two promising approaches of applied research and practice that might support meaningful processes for advancing evidence-informed health equity action. It began with informal conversation about our experiences as doctoral students doing research for health equity, where we found ourselves grappling with contradictions and tensions within our field. Though we witnessed a broad commitment to 'good' equity intentions, we simultaneously observed processes and leadership that contradicted the evidence on causes and applauded superficial responses to health inequities. Critically examining how to move beyond good intentions for health equity became central to both of us in our doctoral research, with Katrina focusing on integrated knowledge translation (IKT) and Julia on global health governance (GHG). As our dialogue became more purposeful and structured, we discovered that the challenges we encountered in our respective fields were met by strengths in the other. Adopting an intentionally optimistic lens, we explored how these fields might complement each other and, through deeper attentiveness to issues of political power, could collectively contribute to more productive health equity action.

We understand both IKT and GHG to be primarily concerned with processes. IKT brings together people who do and use research as equal contributors to processes of collaboratively identifying and responding to knowledge-to-action challenges [25-28]. Ideally, GHG brings cross-sector actors together to deliberate and guide mechanisms for resolving complex global issues through intentional collaboration $[29,30]$. Both are promising, yet the strengths of each mirror weaknesses in the other. Poor governance suffers from accountability and administrative failures, and a lack of strategy for integrating evidence-informed, contextual and tacit knowledges [31-33]. Emerging from health systems settings with clearly defined and contained contexts (e.g. clinical practice sites), IKT suffers a lack of attention to power dynamics and complexity in decision-making [27], making it difficult to apply to 'wicked' knowledge-to-action problems. Further, despite much interest in both IKT and GHG within the field of health equity, their respective bodies of literature are disconnected.

In this article, we draw on Freire and Shor's metaphor of a 'dialogic table' [34], inviting contemplation of how blending IKT approaches with GHG principles could support meaningful health equity action. Below, we lay a foundation for deeper, critically reflective consideration of the complementarities of IKT and GHG. We are inspired by the potential of critical pedagogy as an epistemological guide for 'how' we (society, scientists, practitioners, decision-makers, etc.) might collectively inspire transformative possibilities. In their reflective conversation about learning, Freire and Shor described a 'dialogic table' as an enabler of transformative co-learning. They suggested an "object to be known is put on the table between subjects... [who] meet around it and through it for mutual inquiry" ([34], p. 14). The "object to be known" in this dialogue is evidence-informed health equity action. The 'subjects of knowing, each with their own insights, knowledges (e.g. tacit, institutional, professional knowledges), evidences and epistemologies, are people situated within the fields of IKT and GHG. We set this dialogic table by discussing the wickedness of health inequities, the strengths and limitations of IKT and GHG, and how to leverage their mutually beneficial characteristics.

\section{Unpacking the wickedness of health inequities}

Health inequities are systematic differences in health rooted in socioeconomic and political injustices [14]. The WHO Commission on Social Determinants of Health described health inequities as avoidable, arising from "...the conditions of daily life in which people are born, grow, live, work, and age" shaped by social, political and economic forces, and requiring response from the "whole of government" [14]. Evidence shows that the greater the gap between a population's richest and poorest, the greater the differences in health between them $[3,35,36]$. Unequal and unfair systems of power between and within nation states are widely recognised as driving forces in the creation of structures that disproportionately advantage some lives at the cost of others $[8,14,37]$. Though the evidence about causal roots is clear, and a robust suite of tested policy recommendations widely available [15-18], the implementation of policy solutions is far from straightforward. Calls for social policy reform to improve health have been documented for more than 160 years [38, 39], revealing 
deep resistance to resolve. Indeed, the causes of health inequities are tenacious because they are rooted socio-political systems and structures designed to reinforce the status quo of power distribution, locally and globally.

Connecting knowledge to action on root causes of health inequities implicates a reconstruction of the systems and structures that shape how society is organised. This infinitely complex work demands sophisticated examination of drivers and disrupters of inequities and a vast imagination for who (and what) should be engaged. This work is challenging for many reasons, not the least of which is a fundamental clash between health inequities' inherent complexity and the dominant lens through which the world is observed and responded to in the field of health and science generally. This lens involves linear, reductionist and hierarchical assumptions (Table 1) stemming from seventeenth-century mechanistic suppositions about reality [20]. A repercussion of these assumptions is a persistent Western habit of understanding "the world as a collection of separable and thus independent units and assumes linear cause-and-effect relationships between these units, and that these relationships are reversible" ([21], p. 3). When these assumptions are at play, our collective capacity to recognise the depth and tenacity of root causes remains elusive.

Lending to a particularly narrowed and superficial lens through which the social determinants of health [20] and health inequities are framed [24, 40], mechanistic assumptions effectively mask complex mechanisms that entrench inequities. Rather than focusing on the intersecting nature of the social determination of health [41], efforts to advance health equity under these assumptions place inordinate attention on behavioural interventions and insufficient attention on structural causes [42, 43]. For example, even when there is agreement about causes, public health efforts tend to focus on interventions that place responsibility for health on individual behaviours [23, 44]. Despite the recognised value of upstream and structural interventions, research shows a predominantly downstream focus in policy and public health efforts [24, 45-48]. Behavioural interventions for healthy eating, for example, distract attention away from complex issues of affordability and accessibility, whereas a more structural intervention might involve advocacy to advance socially protective policy for living wages.

Further, the role of power in establishing systematic advantage and disadvantage, recognised as a pivotal driver of health inequities [14], is only occasionally acknowledged and infrequently used to guide study goals and objectives [40]. Decades of dominant neoliberal ideology [47] have contributed to policy environments incompatible with the kinds of social protection known to mitigate health inequities $[47,49,50]$. Compounding these incompatibilities is a preoccupation with individualism and bio-behaviourism in health sciences that conflicts with the best available evidence and often distracts attention from where it might be most productive [24, 40,51,52]. Whether inadvertent or strategic, the absence of power analysis in efforts to advance health equity action can undermine possibilities of uprooting the tenacious systems of power that lead to inequities.

The fields of GHG and IKT span practice, policy and research outside the confines of a particular topic. Both fields bring something important to the table in response to health inequities. Further, because of their relational nature, they both offer platforms for the kind of dialogue necessary to challenge reductionism and mitigate power imbalances. Greater integration across disciplines interested in health equity is recognised as necessary evidence-informed action for health equity $[53,54]$. If there is indeed desire and capacity to begin unravelling equity-harming structures, power and policy environments, then there is an urgent need to understand how to mobilise knowledge into action - both in terms of increasing the application of existing knowledge and informing emerging research. Unpacking these influences could provide a useful means of deconstructing underlying assumptions that lend themselves to consistent failures to advance health equity.

Table 1 Mechanistic assumptions and their application to social determinants of health ${ }^{\mathrm{a}}$

\begin{tabular}{|c|c|c|}
\hline Assumption & Description & How the assumption circumvents complexity of health inequities \\
\hline Reductionism & $\begin{array}{l}\text { Assumes the whole system can be understood by identifying, } \\
\text { describing and analysing all of its constituent parts }\end{array}$ & $\begin{array}{l}\text { Breaks social determinants of health into separate, distinct factors } \\
\text { (rather than a set of complex intersecting factors) } \\
\text { Draws attention to symptoms or expressions of root causes that } \\
\text { are more immediately visible (e.g. considering 'race' a } \\
\text { determinant of health instead of 'racism') }\end{array}$ \\
\hline Linearity & $\begin{array}{l}\text { Assumes that (1) output changes proportionally with input, } \\
\text { and (2) the effect of combined inputs can be understood } \\
\text { and predicted by dissecting the input-output relationships } \\
\text { of individual components, or a direct summative and } \\
\text { predictive cumulation of constituent parts }\end{array}$ & $\begin{array}{l}\text { Simplifies interconnectedness } \\
\text { Justifies use of proxy indicators that reflect symptoms rather than } \\
\text { causes of health inequities (e.g. monitoring maternal and child } \\
\text { mortality rates as indicators of equity) }\end{array}$ \\
\hline Hierarchy & $\begin{array}{l}\text { Assumes central power and control, which diffuses } \\
\text { systematically from proximal to more distal parts }\end{array}$ & $\begin{array}{l}\text { Places responsibility for acting on health within individuals or } \\
\text { groups, rather than society } \\
\text { Legitimises a focus on health damaging behaviours rather than } \\
\text { health damaging conditions, systems or structures }\end{array}$ \\
\hline
\end{tabular}




\section{What does IKT bring to the table?}

Efforts to respond to health inequities include explicit calls for connecting research to action [14, 55]. These calls align with the growing recognition of the importance of knowledge translation (KT) [56-59]. IKT offers strategies for bringing diverse perspectives together to understand and respond to problems through processes of knowledge generation and refinement [25-27]. Inherently relational [60], IKT is non-linear and challenges traditional notions of the dispassionate, objective 'expert researcher' [61] whose work, once released into the world through scholarly publication, carries de facto impact. It involves participatory, inclusive processes where people who 'use' research work alongside people who 'do' research [62]. Recognising a 'social contract' between society and science, IKT brings stakeholders into a social process of problem solving through research [63] emphasising knowledge co-production in partnership [27]. By virtue of this collaborative approach to knowledge production, refinement and use, an IKT approach necessitates dialogue and trust building [64-66]. These characteristics are well suited to overcoming mechanistic assumptions by fostering 'change from within'; however, the application of IKT to wicked problems is constrained by underlying assumptions that limit the scope and scale of contexts for which it was originally envisioned.

Frameworks for IKT consistently describe it as a way of collaboratively leveraging the research processes as a means for generating context-sensitive, complexity-embracing, real-life solutions grounded in evidence. Among evolving models for IKT are encouraging innovations, such as the use of critical realism and arts in KT [67], systems thinking [68], and even reflexive frameworks for equity-focused KT [69]. Common among these models is a recognition that "both communities [of knowledge users and producers] hold distinct norms and values but they also bring valuable knowledge to the problem; and the work of knowledge generation is done collaboratively" ([27], p. 620). A distinguishing feature of IKT is, however, that "knowledge users usually have the authority to invoke change in the practice or policy setting" [27]. This presumes that knowledge users are individual 'stakeholders' who represent particular portfolios within a health system or community setting. When the context and knowledge-to-action problem implicates social organisation and structure, however, the idea of including everyone, or even of finding just one set of stakeholders who may have authority to invoke change over some aspect of policy or practice relevant to health equity can be paralysing. The need for engaging people who can be part of decision-making mechanisms that lead to action opens a question of governance.

Although IKT models demonstrate promise for micro(e.g. clinical practice unit) and meso- (e.g. health systems) contexts [70], their utility is limited when applied to the multiple, complex actors that contribute to shaping political, social and cultural environments that either drive, do nothing or disrupt wicked problems like health inequities. This is, in part, due to the difficulty of navigating meaningful engagement within the vastness of potential actors to include. Rather than focusing stakeholder analysis [71] in a defined setting, the range of potential actors implicated in wicked problems extends to networks of knowledge producers and knowledge users, many of which are not single entities, but conglomerates that also produce multiple competing interests and values. Identifying the 'right' actors to engage could become in and of itself a wicked problem, resistant to resolve and surely beyond the scope of any individual study or programme of research. Further, these models lack direction for how to achieve cohesiveness toward a common goal. Additionally, despite a need for evidence-informed policy and practice for health $[14,17]$, there are few examples of using IKT approaches to respond to wicked problems. These features that constrain the application of IKT in the face of wicked problems could be redressed through adoption of the principles of GHG, particularly its mechanisms of legitimacy and collaboration between multi-sector transnational actors, with an emphasis on civil society.

\section{What does GHG bring to the table?}

As a reaction to the intensifying wickedness of health problems that defy state borders, governance processes consist of stakeholders working through formal international institutions both within and across borders. Heavily influenced by major globalisation events such as HIV/AIDS and SARS, current mechanisms and processes for GHG stem from the disciplines of political science, health economics and health policy [72, 73]. In the absence of a singular global government, GHG platforms convene a plurality of major actors to define shared values, establish standards and regulatory frameworks, set priorities, mobilise and align resources, and promote research. GHG often requires individual governments to forgo aspects of their individual sovereignty in order to collaborate and participate with international agencies such as WHO [74]. For example, the WHO International Health Regulations establishes standards for how individual countries respond to international health risks [75]. These regulations refer to the need for the Director-General of WHO to consider scientific evidence, but do not provide recommendations for how this evidence could inform decision-making.

Ultimately, GHG is a polycentric system that provides a mechanism for collective decision-making for improved health through the interplay of different institutional forms and actors at different levels in pursuit of common goals $[29,73,76]$. The imperfect decision-making processes of GHG are, however, embedded in historical and socio-political contexts of colonialism and heavily 
influenced by power relationships, values, norms, organisational structures and resources. GHG is political; it can serve to reinforce or challenge existing institutional exclusion and power inequalities and has direct impacts on health system equity whereby the decisions made through GHG processes shape who accesses benefits and whose voices are heard [77]. Continued processes of globalisation and increasing influence of private sector actors in global health bring new layers of political power to the governance scene [78], while innovations in technology, data, communications and networks open possibilities for reimagining the mechanisms and processes relied upon post World War II [79]. The time is ripe for reimagining how GHG might better support collective responses to global problems.

At the turn of the twenty-first century, health sectors worldwide were acutely aware of their limited capacity to deal with emerging challenges in isolation. Global vulnerability to pandemics, climate change and political instability all contribute to a growing recognition of a need for multi-sectorial action and broad public and private partnerships at national and international levels [74]. Further, civil society and political leaders are challenging notions of an isolated, technocratic health sector and call for more unified attention to issues of equity and human rights [73]. Society writ large voiced a desire to be part of the political sphere that shapes their life circumstances, opportunities and experiences of health and healthcare. In response to a confluence of heightened awareness of the globalised nature of health issues and growing demand for collective responses, complex networks of international agencies and philanthropic foundations collaborated to set global targets for progress toward a more equitable word through the Millennium Development Goals and the more recent Sustainable Development Goals [33, 80]. These and other examples of governance for health equity (e.g. the WHO Commission on Social Determinants of Health) are key demonstrations of the kinds of platforms and mechanisms GHG offers. Importantly, these mechanisms also demonstrate how the legacy of colonialism contributes to health equity failures.

Global health crises exemplify how health equity is tied up to socio-political and economic contexts, including the histories of colonisation. The 2014-2016 Ebola epidemic is an important example of the consequences of governance failures. As outbreaks emerged, the world witnessed vulnerabilities and fragmentation in public service sectors that became determinants of who lived and who died revealing intense inequities between and within countries [81-83]. Leaders in health systems and governments alike recognised the need for strong global institutions, mechanisms and funding for development of global public goods that contribute to resolving global health threats. In the case of the Ebola crisis, GHG leadership (e.g. WHO) failed to respond in a timely manner, which lead to other key actors stepping up to fill the leadership gap. The response was openly criticised as "too little too late" to halt an epidemic reflective of the "pathology of society and the global and political architecture" [84]. Like many contemporary GHG challenges, this crisis unfolded through the legacy of colonialism [85] that holds the roots of inequities in place. By revealing the differential value placed on human life globally, these failures illuminated the tenacious nature of health inequities and the lack of political will to uproot their causes.

While GHG provides a platform for responding to wicked problems through global collaboration, cooperation and leadership among a diverse set of actors, GHG deliverables still lack strategies to ensure evidence- [86] and equity-informed [87] policy, practice and decision-making. The 2014 Lancet-University of Oslo Commission on Global Governance for Health also pushed for evidence- and equity-informed GHG, recommending mandatory health equity impact assessments for all global institutions and strengthened sanctions against non-state actors for rights violations [88]. Surprisingly, there are few examples of looking to IKT to support processes for the same [89]. Shared governance and public dialogue about our social and economic architecture is needed [90], where public moral norms can be re-constructed and internalised (e.g. recreating constructs of health equity as a public good). IKT approaches and strategies could support this kind of dialogue in engaged, inclusive ways that support connecting this kind of evidence and other knowledges with action. In Table 2, we offer an overview of recognized steps in the knowledge-to-action cycle [25] alongside complementary GHG processes and mechanisms. This blended IKT-GHG approach, done alongside a critical examination of power, presents a promising pathway toward health equity action.

\section{Additional 'objects' of consideration on this dialogic table}

In addition to our interest in leveraging the relational-dialogic nature of GHG and IKT to counter reductionism and mitigate power imbalances, we propose placing a few additional objects on this dialogic table, namely accountability, leadership and inclusion. It is beyond the scope of this discussion to resolve the intricacies of any of these issues, but we hope that they serve as sparks for continued dialogue and reflection. In GHG, the lack of accountability of major global health organisations (i.e. WHO), and its relationship to systems of power, has been a significant challenge [74]. Unclear accountabilities, particularly for leadership, can play a role in legitimising investments in research, IKT, or policy in ways that overlook evidence about causal roots or reinforce inequitable power $d y$ namics. Without frank acknowledgement of the legacies 
Table 2 Blending processes and mechanisms for a blended integrated knowledge translation (IKT) - global health governance (GHG) approach

\begin{tabular}{lll}
\hline Moments in the IKT cycle & Complementary GHG processes and mechanisms & Examining Power in an IKT-GHG Approach \\
\hline Identify problem and identify, review, & Governance bodies that work together to identify & Taking steps to balance power between global \\
select knowledge & problems and knowledge & North and global South \\
$\downarrow$ & Consideration of the composition of non-traditional & Promoting transparency and accountability in \\
Ádapt knowledge to local context & actors, such as civil society and private sector, in & decision-making about the composition of \\
$\downarrow$ & governance bodies & governance bodies \\
& Guidance for meaningful engagement between & Attentiveness to how particular ways of framing \\
& actors, particularly in shared governance models & health and governance influences how a \\
& Promising example: GAVI mitigates known global & 'problem' is being understood \\
& power imbalances through the composition of & Attentiveness to how historical conditions and \\
& their Board, which includes 9 neutral individuals & power dynamics privilege particular assumptions
\end{tabular}

$\downarrow$ Select, tailor, implement interventions

$\downarrow$
Assess barriers to knowledge use who speak to public interests, 5 government representatives each from donor and recipient countries, 1 expert in research and technology, 1 industry representative each from the global South and global North, 1 civil society representative, and 1 representative each from WHO, UNICEF, World Bank and Bill \& Melinda

Gates Foundation

Guidance on how to resolve discrepant norms and values between engaged actors

Guidance on how to ensure legitimacy of leadership

Guidance on how political will and power influence this process

Platforms for coordinating global-level responses to wicked problems

Promising example: The Lancet Commission on GHG offered specific recommendations for governance mechanisms and processes, with detailed calls to make the examination of issues of power an explicit responsibility of GHG. They called for attention to democratic deficit, institutional and structural inflexibility, strengthened accountability, identification and involvement of missing institutions and voices, and to create a policy space for health. Their report offers specific guidance on how to do so. Among the Commission's recommendations were specific mechanisms, including a proposed UN Multi-stakeholder Platform on Global Governance for Health

Monitor knowledge use

$\downarrow$

Evaluate outcomes

$\downarrow$

Sustain knowledge use
Generation and maintenance of mechanisms provide infrastructure for monitoring and evaluation Norms and expectations for transparency in decision-making

Promising example: Two advisory bodies, the Technical Review Panel and a Technical Evaluation Reference Group, provide independent audit and monitoring of programmes funded by the GFATM. Their reports highlight lessons learned from funding requests and reviews, including perspectives of applicants, technical partners, the Secretariat and the Board. They consist of external experts in HIV, TB and malaria as well as experts in human rights, gender, health systems and sustainable financing. Their reports are made publicly available through the GFATM website
Attentiveness to how historical conditions and power dynamics give rise to inequities in inclusion and voice

Exploration of how processes of historical exclusion (e.g. due to race, class, gender, Indigeneity, etc.) can be mitigated

Attentiveness to who decides what knowledge count as legitimate

Attentiveness to who decides what outcomes count as legitimate

Consideration of who owns knowledge, with efforts to promote publicly owned and accessible data

Attentiveness to equitable distribution of resources and benefits of colonisation, and particularly at a time when neoliberal reason and monetisation of socio-political processes undermine democratic governance $[85,91]$, it is insufficient to assume health equity is the responsibility of governments, government agencies or civil society, nor of international institutions, such as WHO or United
Nations, whose political leverage falls under the shadow of powerful financial bodies such as the World Trade Organization, International Monetary Fund, World Bank and, more recently, influential and well-endowed philanthropic foundations such as the Bill \& Melinda Gates Foundation $[78,79]$. Neither can the roles, responsibilities 
and accountabilities of 'researchers' and 'research users' in IKT be simply assumed because they agree to work together. These are critical considerations in moving toward evidence-informed, equitable governance for health equity action.

Systems for enabling accountability and transparency must be agreed to, which raises questions of meaningful participation and responsibility [30]. Despite intense imbalances in power and interests, the challenge for GHG and IKT strategists alike will be to engage a plurality of actors in ways that enable collective agreement on a common goal. Accountability extends to issues of inclusion and exclusion and how power is distributed. Though inclusion is widely recognised as important for GHG and $\mathrm{KT}$, how to achieve it is elusive. Global events exemplify ways in which civil society is pushing back on systems of exclusion, voicing a desire to transform what are, in essence, governance processes. Responses to global health issues evolve in politicised systems that exclude the voices of those most burdened by health inequities [92]. The Idle-No-More [93], Occupy [94], Black Lives Matter [95] and the more recent \#metoo movements share a common outcry for justice and equity in society, pointing to the inequities generated by power and policy structures that systematically privilege the wealthy and White. Collectively, these movements reflect a growing public demand for politics of inclusion where government and non-government actors are held accountable for the consequences of their action (or inaction). They are demonstrative of how intricately tied up health inequities are in complex, competing systems of power within which there is a need for critical analysis and mitigation.

Further, the likelihood of understanding complexity becomes much greater by directly fostering balanced representation that includes a pluralism of voices. On a larger scale, this is reflected in the evolution of the major GHG players in the world. Historically, WHO and the World Bank have been primarily responsible for GHG, but given the significant frustration with each of these institutions' poor GHG, two new organisations have risen, namely The Global Fund for AIDS, TB, and Malaria (GFATM) and Global Alliance for Vaccines and Immunization (GAVI); what separates these two institutions from their counter parts are their commitment to GHG. These commitments include a wider, more inclusive, Board of Governors (civil society, the private sector, and philanthropic organisations), as well as providing clear and transparent (i.e. publicly available) decision-making regarding funding decisions and priority-setting processes. Both organisations rely on external review for their accountability for decision-making processes like funding decisions. We believe that theory and practice in both IKT and GHG would benefit from these new examples of creating organisations that work toward governance models based on inclusion, voice, transparency and accountability. Without clear leadership and a commitment to accountability through transparency by all global health actors, the current response to health inequities will be ad hoc and exclusive of these civil society voices, as well as highly fragmented with little to no formal mandate between the players. Importantly, the response would be at risk of remaining distracted by the tendency to focus on symptoms rather than causes.

As the field of IKT evolves, so too do opportunities for theory and practice refinement. Governance processes could enhance current IKT frameworks to open considerations of how to weave evidence into decision-making while acknowledging conflicting norms and values within the political sphere under which it operates. Using shared health governance theory to drive this examination can contribute to more transparent and equity-centred approaches to understanding how these norms and values shape health problems [90]. Expanding IKT models to include governance would require re-examining legitimacy, transparency, power and inclusion in the process of connecting knowledge with action. This broader conceptualisation extends the application of IKT into a complex public sphere, across domains and outside the control or context of any one institution or set of actors. We are much more likely to approach understanding complexity through systems of inclusion that directly engage multiple socio-political arenas. Systems of inclusion can be explicitly addressed by adopting principles of GHG alongside the strategies of IKT.

Exploring a blended IKT-GHG approach could extend insights from the success of IKT in clinical and health systems settings $[70,96]$ to wicked problems. This approach could illuminate new ways of thinking about how we might influence the trajectory of wicked problems to fair, equitable governance informed by high quality, rigorous and relevant research. In the example we offer here, of moving toward health equity, IKT implicates an all-of-society approach because the root causes involve all of society. IKT models already acknowledge the process of connecting knowledge with action as inherently social, but this is often used as a way to describe the processes involved in well-defined settings. Wicked problems are not confined to singular contexts. Although attending to social processes are important, they need to be considered in the broader sphere of how society is organised. This means thinking about and connecting the best available knowledge about a wicked problem to evidence-informed action as a 'public good', wherein the process is integrated as part of the social fabric around which communities are organised. We believe broadening the application of approaches to IKT across multiple layers of complex social interactions can support evidence-informed influence and, again, GHG can support the achievement of coherency in doing so. 


\section{Conclusion}

In this article, we set a dialogic table to explore how blending principles of GHG with IKT strategies could leverage the strengths of both, enhancing the possibility for effective and evidence-informed answers to wicked problems. We situated this table in a global political economy that unfairly distributes power, resources and money. By focusing on explicit examination of power and overcoming mechanistic assumptions that draw attention away from the root causes of health inequities, there is tremendous potential to be leveraged in a combined IKT and GHG approach. Such an approach would require leadership from academic, policy and civil society arenas wherein existing GHG platforms explicitly embrace a commitment to connecting knowledge (evidence about causes) with action. We encourage those pursuing an IKT-GHG approach to engage in bold and inclusive dialogue about how socio-political histories (e.g. colonisation) are at play in the ways they frame or respond to health inequities. In contemplating governance-focused IKT, actors involved in advancing health equity can take promising steps toward inclusion of a broad spectrum of actors and a pathway for stimulating the collective agency needed to affect change on this wicked problem.

\section{Abbreviations}

GHG: global health governance; IKT: integrated knowledge translation; $\mathrm{KT}$ : knowledge translation

\section{Acknowledgements}

We wish to acknowledge the mentorship, encouragement and scholarly guidance we receive from our supervisory committees as doctoral candidates. For KP, at the University of British Columbia, this includes Dr Joan Bottorff, Dr Susana Caxaj, Dr lan Graham, and Dr Michael Burgess. For JP, at McMaster University, this includes Dr Lisa Schwartz, Dr Susan Jack, Dr Claudia Emmerson, and Dr Brian Cameron.

\section{Funding}

This paper was commissioned by the Integrated Knowledge Translation Network (IKTRN). The IKTRN brings together knowledge users and researchers to advance the science and practice of IKT and train the next generation of IKT researchers. Honorariums were provided for completed papers. The IKTRN is funded by a Canadian Institutes of Health Research Foundation Grant (FDN\#143247). Further, the article emerged from the doctoral dissertation work of both authors. KP's doctoral studies are funded through a Banting and Best Canada Research Scholar award from the Canadian Institutes of Health Research. JP's doctoral studies are funded through Banting and Best Canada Research Scholar and the Douglas Kinsella Award in Bioethics from the Canadian Institutes of Health Research.

\section{Availability of data and materials}

Not applicable.

\section{Authors' contributions}

KP provided coordination and leadership for the preparation of the manuscript. The content for this debate article was generated through a series of conversations to which KP and JP contributed equally. Both authors brought a strong grounding research and science related to health equity. KP provided more content related to integrated knowledge translation, JP provided more content related to governance. Both authors read and approved the final manuscript.

\section{Authors' information}

$\mathrm{KP}$ is a Regional Practice Leader for Research \& Knowledge Translation at Interior Health. In her role, she supports IKT through teaching, mentoring, consulting, and leading IKT and equity-centred research.

Ethics approval and consent to participate

Not applicable.

\section{Consent for publication}

Not applicable.

\section{Competing interests}

The authors declare that they have no competing interests.

\section{Publisher's Note}

Springer Nature remains neutral with regard to jurisdictional claims in published maps and institutional affiliations.

\section{Author details}

${ }^{1}$ University of British Columbia, 3333 University Way, Kelowna, BC, Canada. ${ }^{2}$ McMaster University, 1280 Main Street West, Hamilton, ON, Canada. ${ }^{3}$ Interior Health, 505 Doyle Avenue, Kelowna, BC, Canada.

Received: 14 November 2018 Accepted: 6 February 2019

Published online: 04 March 2019

References

1. Rittel HWJ, Webber MM. Dilemmas in a general theory of planning. Policy Sci. 1973:4:155-69.

2. Waddock S. The wicked problems of global sustainability need wicked (good) leaders and wicked (good) collaboraative solutions. J Manag Glob Sustain. 2013;1:91-111.

3. Labonte $\mathrm{R}$, Schrecker $\mathrm{T}$. The state of global health in a radically unequal world: Patterns and prospects. In: Benatar SR, Brock G, editors. Global Health and Global Health Ethics. Cambridge: Cambridge University Press; 2011. p. 24-36.

4. Donkin A, Goldblatt P, Allen J, Nathanson V, Marmot M. Global action on the social determinants of health. BMJ Global Health. 2018;3(Suppl 1):e000603.

5. Petticrew M, Tugwell $P$, Welch $V$, Ueffing E, Kristjansson E, Armstrong R, et al. Cochrane update: better evidence about wicked issues in tackling health inequities. J Public Health. 2009;31:453-6.

6. McNeill D, Birkbeck CD, Fukuda-Parr S, Grover A, Schrecker T, Stuckler D. Political origins of health inequities: Trade and investment agreements. Lancet. 2016;389:760-2.

7. Buse C. Intersectoral action for health equity as it relates to climate change in Canada: Contributions from critical systems heuristics. J Eval Clin Pract. 2013;19:1095-100.

8. Came H, Griffith D. Tackling racism as a "wicked" public health problem: enabling allies in anti-racism praxis. Soc Sci Med. 2018;199:181-8.

9. Blackman T, Hunter D, Marks L, Harrington B, Elliott E, Williams G, et al. Wicked comparisons: Reflections on cross-national research about health inequalities in the UK. Evaluation. 2010;16:43-57.

10. Raphael D. A discourse analysis of the social determinants of health. Crit Public Health. 2011;21:221-36.

11. Pauly B, Shahram S, Dang P, Marcellus L, MacDonald M. Health equity talk: understandings of health equity among health leaders. AIMS Public Health. 2017;4:490-512. https://doi.org/10.3934/publichealth.2017.5.490.

12. Walls $\mathrm{H}$, Baker $\mathrm{P}$, Parkhurst J. Addressing trade policy as a macro-structural determinant of health: The role of institutions and ideas. Glob Soc Policy. 2018:18:94-101.

13. Green J, Buckner S, Milton S, Powell K, Salway S, Moffatt S. A model of how targeted and universal welfare entitlements impact on material, psychosocial and structural determinants of health in older adults. Soc Sci Med 2017:187:20-8.

14. Commission on Social Determinants of Health. Closing the Gap in a Generation: Health Equity Through Action on the Social Determinants of Health. Geneva: WHO; 2008. http://www.who.int/social_determinants/final_ report/csdh_finalreport_2008.pdf

15. World Health Organization. Health in All Policies (HiAP) framework for country action. Health Promot Int. 2014;29(Suppl 1):i19-28.

16. World Health Organization. Rio Political Declaration on Social Determinants of Health. Rio de Janeiro: WHO Country Office; 2011. 
17. Global Ministerial Forum for Research on Health. Bamako Call to Action on Research for Health: Strengthening Research for Health, Development, and Equity. Bamako; 2008.

18. Shankardass K, Muntaner C, Kokkinen L, Shahidi FV, Freiler A, Oneka G, et al. The implementation of Health in All Policies initiatives: a systems framework for government action. Health Res Policy Syst. 2018;16:26.

19. Raphael D, Brassolotto J. Understanding action on the social determinants of health: a critical realist analysis of in-depth interviews with staff of nine Ontario public health units. BMC Res Notes. 2015;8:105.

20. Jayasinghe $\mathrm{S}$. Conceptualising population health: from mechanistic thinking to complexity science. Emerg Themes Epidemiol. 2011;8:2. https://doi.org/ 10.1186/1742-7622-8-2

21. Rogers KH, Luton R, Biggs H, Biggs R, Blignaut S, Choles AG, et al. Fostering complexity thinking in action research for change in social-ecological systems. Ecol Soc. 2013;18:31. https://doi.org/10.5751/ES-05330-180231.

22. Labonté R. Health promotion in an age of normative equity and rampant inequality. Int J Health Policy Manag. 2016;5:675-82.

23. Cohen BE, Marshall SG. Does public health advocacy seek to redress health inequities? A scoping review. Health Soc Care Community. 2017;25:309-28.

24. Brassolotto J, Raphael D, Baldeo N. Epistemological barriers to addressing the social determinants of health among public health professionals in Ontario, Canada: a qualitative inquiry. Crit Public Health. 2013;24:321-36. https://doi.org/10.1080/09581596.2013.820256

25. Graham ID, Logan J, Harrison MB, Straus SE, Tetroe J, Caswell W, et al. Lost in knowledge translation: Time for a map? J Contin Educ Health Prof. 2006; 26:13-24.

26. Kothari A, Wathen CN. A critical second look at integrated knowledge translation. Health Policy. 2013;109:187-91.

27. Kothari A, Wathen CN. Integrated knowledge translation: digging deeper, moving forward. J Epidemiol Community Health. 2017;71:619-23.

28. Ottawa Hospital Research Institute. Integrated Knowledge Translation Research Network. 2018. https://iktrn.ohri.ca. Accessed 21 Jan 2018.

29. Kickbusch I, Szabo MMC. A new governance space for health. Glob Health Action. 2014;7:23507. https://doi.org/10.3402/gha.v7.23507.

30. Dodgson R, Lee K, Drager N. Global Health Governance: A conceptual review. Geneva; 2002.

31. Kickbusch I. Global health governance challenges 2016: are we ready? Int J Health Policy Manag. 2016:5:349-53. https://doi.org/10.15171/ijhpm.2016.27.

32. Frenk J, Moon S. Governance challenges in global health. N Engl J Med. 2013;368:936.

33. Gostin LO, Mok EA. Grand challenges in global health governance. Br Med Bull. 2009;90:7-18. https://doi.org/10.1093/bmb/ldp014.

34. Shor I, Freire P. What is the "dialogical method" of teaching? J Educ. 1987; 169:11-31.

35. Marmot M. Fair society, healthy lives: The Marmot Review; 2012.

36. Ottersen OP, Dasgupta J, Blouin C, Buss P, Chongsuvivatwong V, Frenk J, et al. The political origins of health inequity: Prospects for change. Lancet. 2014;383:630-67.

37. Forman $L$. The ghost Is the machine: How can we visibilize the unseen norms and power of global health? Comment on "Navigating between stealth advocacy and unconscious dogmatism: The challenge of researching the norms, politics and power of global health.". Int J Health Policy Manag. 2015:5:197-9. https://doi.org/10.15171/ijhpm.2015.206.

38. Brown TM, Fee E. Rudolf Carl Virchow: medical scientist, social reformer, role model. Am J Public Health. 2006;96:2104-5. https://doi.org/10.2105/AJPH. 2005.078436.

39. Monteiro LA. Florence Nightingale on public health nursing. Am J Public Health. 1985;75:181-6. https://doi.org/10.2105/AJPH.75.2.181.

40. Plamondon K, Bottorff JL, Graham ID, Caxaj CS. The integration of evidence from the Commission on Social Determinants of Health in the field of eealth equity: a scoping review. Crit Public Health. 2018. https://doi.org/10. 1080/09581596.2018.1551613.

41. Spiegel JM, Breilh J, Yassi A. Why language matters: Insights and challenges in applying a social determination of health approach in a North-South collaborative research program. Glob Health. 2015;11:9.

42. SJE M, DEE K. Change Matters: Critical Essays on Moving Social Justice Research from Theory to Policy. Critical Qualitative Research. New York: Peter Lang; 2010.

43. Kirkland R, Raphael D. Perpetuating the utopia of health behaviourism: a case study of the Canadian Men's Health Foundation's Don't Change Much initiative. Soc Theory Health. 2017;16:1-19.
44. Lucyk K, McLaren L. Taking stock of the social determinants of health: a scoping review. PLoS One. 2017;12(5):e0177306.

45. Carey G, Crammond B. Action on the social determinants of health: views from inside the policy process. Soc Sci Med. 2015;128:134-41.

46. Gore D, Kothari A. Social determinants of health in Canada: Are healthy living initiatives there yet? A policy analysis. Int J Equity Health. 2012;11:41.

47. Raphael D. Beyond policy analysis: the raw politics behind opposition to healthy public policy. Health Promot Int. 2015;30:380-96.

48. Raphael D, Brassolotto J, Baldeo N. Ideological and organizational components of differing public health strategies for addressing the social determinants of health. Health Promot Int. 2014;30:855-67.

49. Bryant T, Raphael D, Schrecker T, Labonte R. Canada: a land of missed opportunity for addressing the social determinants of health. Health Policy. 2011;101:44-58. https://doi.org/10.1016/j.healthpol.2010.08.022.

50. Raphael D, Curry-Stevens A, Bryant T. Barriers to addressing the social determinants of health: insights from the Canadian experience. Health Policy. 2008;88:222-35. https://doi.org/10.1016/j.healthpol.2008.03.015.

51. Hanson L. From reflexivity to collectivity: challenging the benevolence narrative in global health. Can Med Educ J. 2017;8:e1-3.

52. Baum F, Fisher M. Why behavioural health promotion endures despite its failure to reduce health inequities. Sociol Health IIIn. 2014;36:213-25.

53. Forman L, Cole DC, Ooms G, Zwarenstein M. Human Rights and Global Health Funding: What Contribution can the Right to Health Make to Sustaining and Extending International Assistance for Health? Global Health Governance. 2012; https://blogs.shu.edu/ghg/2012/12/31/human-rightsand-global-health-funding-what-contribution-can-the-right-to-health-maketo-sustaining-and-extending-international-assistance-for-health/. Accessed 10 Jan 2018.

54. Baptiste D, Kapungu C, Khare MH, Lewis Y, Barlow-Mosha L. Integrating women's human rights into global health research: An action framework. J Women's Health. 2010;19:2091-9. https://doi.org/10.1089/jwh.2010.2119.

55. Popay J. The knowledge needed to deliver social justice and health equity. Int J Qual Methods. 2012;11:59-60.

56. Lavis JN. Research, public policymaking, and knowledge-translation processes: Canadian efforts to build bridges. J Contin Educ Health Prof. 2006;26:37-45. https://doi.org/10.1002/chp.49.

57. Pauly BB, MacDonald M, Hancock T, Martin W, Perkin K. Reducing health inequities: the contribution of core public health services in BC. BMC Public Health. 2013;13:550

58. Davison CM, Ndumbe-Eyoh S, Clement C. Critical examination of knowledge to action models and implications for promoting health equity. Int J Equity Health. 2015;14:49. https://doi.org/10.1186/s12939-015-0178-7.

59. Milat AJ, Li B. Narrative review of frameworks for translating research evidence into policy and practice. Public Health Res Pract. 2017;27:13.

60. Bowen S, Botting I, Graham ID, Huebner L. Beyond "Two Cultures": Guidance for establishing effective researcher/health system partnerships. Int J Health Policy Manag. 2016;6:27-42.

61. Rose G. Situating knowledges: positionality, reflexivities and other tactics. Prog Hum Geogr. 1997;21:305-20. https://doi.org/10.1191/ 030913297673302122.

62. Bowen S, Graham ID. From knowledge translation to engaged scholarship: promoting research relevance and utilization. Arch Phys Med Rehabil. 2013; 94(1 Suppl):S3.

63. Gibbons M. The New Production of Knowledge: The Dynamics of Science and Research in Contemporary Societies. Thousand Oaks, London: SAGE Publications; 1994

64. Bowen S, Martens P. Demystifying knowledge translation: learning from the community. J Health Serv Res Policy. 2005;10:203-11.

65. Bowen S. Engaged scholarship, knowledge translation, and PR. In: Higginbottom G, Liamputtong P, editors. Participatory Qualitative Research Methodologies in Health. Thousand Oaks, London: SAGE; 2015. p. 183-99.

66. Pettman TL, Armstrong R, Pollard B, Evans R, Stirrat A, Scott I, et al. Using evidence in health promotion in local government: contextual realities and opportunities. Health Promot J Aust. 2013;24:72-5. https:// doi.org/10.1071/HE12902.

67. Kontos PC, Poland BD. Mapping new theoretical and methodological terrain for knowledge translation: contributions from critical realism and the arts. Implement Sci. 2009:4:1. https://doi.org/10.1186/17485908-4-1.

68. Best A, Holmes B. Systems thinking, knowledge, and action: towards better models and methods. Policy Press. 2010;6:145-59. 
69. Masuda JR, Zupancic T, Crighton E, Muhajarine N, Phipps E. Equity-focused knowledge translation: A framework for "reasonable action" on health inequities. Int J Public Health. 2014;59:457-64.

70. Gagliardi AR, Berta W, Kothari A, Boyko J, Urquhart R. Integrated knowledge translation (IKT) in health care: a scoping review. Implement Sci. 2016;11:38.

71. Bennett G, Jessani N. The Knowledge Translation Toolkit: Bridging the know-do gap: a resource for researchers. Ottawa: International Research Development Centre; 2011.

72. Ulrich B. Power in the Global Age. Cambridge: Policy Press; 2005.

73. Buse K, Hein W, Drager N. Making Sense of Global Health Governance: A Policy Perspective. New York, Houndmills, Basingstoke, Hampshire: Palgrave Macmillan; 2009.

74. Frenk J, Gómez-Dantés O, Moon S. From sovereignty to solidarity: a renewed concept of global health for an era of complex interdependence. Lancet. 2014;383(9911):94-7.

75. World Health Organization. International Health Regulations (2005). Geneva: WHO; 2008. http://www.who.int/ihr/9789241596664/en/. Accessed 25 Feb 2019.

76. Lee K, Kamradt-Scott A. The multiple meanings of global health governance: a call for conceptual clarity. Glob Health. 2014;10:28. https://doi. org/10.1186/1744-8603-10-28

77. Gilson L, Lehmann $U$, Schneider $H$. Practicing governance towards equity in health systems: LMIC perspectives and experience. Int J Equity Health. 2017; 16:171. https://doi.org/10.1186/s12939-017-0665-0.

78. Lee K. How do we move forward on the social determinants of health: the global governance challenges. Crit Public Health. 2010;20:5-14.

79. Smith R, Lee K. Global health governance: we need innovation not renovation. BMJ Glob Health. 2017;2(2):e000275.

80. World Health Organization. Health 8. Partnerships, Interagency Coordination and Resource Mobilization. 2017. http://www.searo.who.int/entity/ partnerships/topics/donors_ghp_h8/en/. Accessed 13 Oct 2017.

81. Grépin K. International donations to the Ebola virus outbreak: too little, too late? BMJ Br Med J. 2015;350:h376. https://doi.org/10.1136/bmj.h376.

82. Boozary AS, Farmer PE, Jha AK. The Ebola outbreak, fragile health systems, and quality as a cure. JAMA. 2014;312:1859-60. https://doi.org/10.1001/jama. 2014.14387.

83. Shoman H, Karafillakis E, Rawaf S. The link between the West African Ebola outbreak and health systems in Guinea, Liberia and Sierra Leone: a systematic review. Glob Health. 2017;13:1. https://doi.org/10.1186/s12992016-0224-2.

84. Sanders D, Sengupta A, Scott V. Ebola epidemic exposes the pathology of the global economic and political system. Int J Health Serv. 2015;45:643-56. https://doi.org/10.1177/0020731415606554.

85. Gill S, Benatar SR. History, structure and agency in global health governance: comment on "Global Health Governance Challenges 2016 - Are We Ready?". Int J Health Policy Manag. 2017;6:237-41.

86. Lee K, Mills A. Strengthening governance for global health research: the countries that most need health research should decide what should be funded. BMJ Br Med J. 2000;321:775-6.

87. CCGHR. CCGHR Principles for Global Health Research. Ottawa: Canadian Coalition for Global Health Research; 2015. http://www.ccghr.ca/resources/ principles-global-health-research/. Accessed 25 Feb 2019.

88. Ottersen OP, Frenk J, Horton R. The Lancet-University of Oslo Commission on Global Governance for Health, in collaboration with the Harvard Global Health Institute. Lancet. 2011;378:1612-3. https://doi.org/10.1016/S01406736(11)61617-6.

89. Lapaige V. "Integrated knowledge translation" for globally oriented public health practitioners and scientists: Framing together a sustainable transfrontier knowledge translation vision. J Multidiscip Healthc. 2010;3:33-47.

90. Prah-Ruger J. Global health governance as shared health governance. J Epidemiol Community Health. 2012;66:653-61.

91. Brown W. Undoing the Demos: Neoliberalism's Stealth Revolution. Brooklyn: Zone Books; 2015.

92. Kapiriri L, Ross A. The politics of disease epidemics: a comparative analysis of the SARS, zika, and Ebola outbreaks. Glob Soc Welf. 2018. https://doi.org/ 10.1007/s40609-018-0123-y.

93. Wotherspoon T, Hansen J. The "Idle No More" movement: paradoxes of First Nations inclusion in the Canadian context. Soc Incl. 2013;1:21-36. https:// doi.org/10.17645/si.v1i1.107.

94. Maharawal MM. Occupy Wall Street and a radical politics of inclusion. Sociol Q. 2013:54:177-81. https://doi.org/10.1111/tsq.12021.
95. Ransby B. The class politics of Black Lives Matter. Dissent. 2015;62:31.

96. Gagliardi AR, Dobrow MJ. Identifying the conditions needed for integrated knowledge translation (IKT) in health care organizations: qualitative interviews with researchers and research users. BMC Health Serv Res. 2016; 16:256. https://doi.org/10.1186/s12913-016-1533-0.
Ready to submit your research? Choose BMC and benefit from:

- fast, convenient online submission

- thorough peer review by experienced researchers in your field

- rapid publication on acceptance

- support for research data, including large and complex data types

- gold Open Access which fosters wider collaboration and increased citations

- maximum visibility for your research: over $100 \mathrm{M}$ website views per year

At BMC, research is always in progress.

Learn more biomedcentral.com/submissions 